\title{
The role of market orientation on market chaos: A case study fast food industry
}

\author{
Mona Hosseinzadeh $^{\mathrm{a}^{*}}$, Masoumeh Sadat Abtahi ${ }^{\mathrm{b}}$ and Kamran Nourbakhsh ${ }^{\mathrm{c}}$
}

${ }^{a}$ Department of Management, Qazvin Branch, Islamic Azad University, Qazvin, Iran

${ }^{b}$ Department of Humanities, Zanjan Branch, Islamic Azad University, Zanjan, Iran

${ }^{c}$ Department of Management and Accounting, South Tehran Branch, Islamic Azad University, Tehran, Iran

\section{H R O N I C L E}

\section{Article history:}

Received October 28, 2013

Received in revised format

25 November 2013

Accepted 19 January 2014

Available online

January 232014

Keywords:

Market orientation

Food industry

Consumer preferences

\section{A B S T R A C T}

This paper investigates the effect of market orientation on small businesses active in fast food industry. Using a simple random method, the study selects a sample 278 fast food units out of approximately 1000 existing restaurants in city of Tehran, Iran. The proposed study designs a questionnaire in Likert scale and distributes it among regular fast food consumers. Using structural equation modeling, the study has detected that there were positive and meaningful relationships between continuous changes on consumer preferences on products and services on one side and market orientation on the other side.

\section{Introduction}

In recent years, a market-oriented corporate culture increasingly has become a primary key of superior corporate performance (Han et al., 1998; \& Elg, 2007; Ruekert, 1992; Hofmeister, 2008; Farrell et al., 2008). There seems to be widespread agreement that optimal new product development programs need a balance between customer-led and lead-the-customer innovation practices. Some people believe that a strong market orientation motivates firms to overemphasize customer-led incremental innovations. The other people think that a strong market orientation could help this balance but confirm that traditional measures of market orientation only capture the kinds of behaviors associated with customer-led incremental innovations. Baker and Sinkula (2007) made use of a national sample of marketing executives and applied a cross-sectional survey design. Measures implemented were market orientation, radical and incremental innovation priority, generative and adaptive learning priority, and new product success. They reaffirmed the position that a strong market orientation could facilitate a balance between incremental and radical innovation by shifting firms' innovation priority more toward radical innovation activities.

*Corresponding author.

E-mail addresses: m almasi2020@yahoo.com (M. Hosseinzadeh) 
Slater and Narver (1995) explained the processes through which organizations may develop and implement new knowledge to help performance. They considered a set of organizational elements that comprise the learning organization and concluded with some recommendations for research to contribute to have insight of learning organizations.

Carmen and Jose (2008) investigated the role of technological and organizational innovation in the relation between market orientation and performance in cultural organizations. They statistically demonstrated that although the linkage between market orientation and performance was significant, what best accounts for enhanced performance was technological and organizational innovation. Hurley and Hult (1998) presented a conceptual framework for incorporating constructs that keep to innovation in market orientation research. Agus and Abdullah (2000) investigated the relationship between total quality management and customer satisfaction.

\section{The proposed study}

This paper presents a study on the effect of market orientation on small businesses active in fast food industry. The main hypothesis of this survey investigates whether there is any relationship between continuous changes on consumer preferences on products and services on one side and market orientation, on the other side. The sample size is calculated as follows,

$n=\frac{N \times z_{\alpha / 2}^{2} \times p \times q}{\varepsilon^{2} \times(N-1)+z_{\alpha / 2}^{2} \times p \times q}$,

where $N$ is the population size, $p=1-q$ represents the yes/no categories, $z_{\alpha / 2}$ is CDF of normal distribution and finally $\varepsilon$ is the error term. Since we have $p=0.5, z_{\alpha / 2}=1.96$ and $N=1000$, the number of sample size is calculated as $n=278$. There are two hypotheses associated with the proposed study of this paper as follows,

1. There is a positive and meaningful relationship between continuous changes on consumer preferences on products and market orientation.

2. There is a positive and meaningful relationship between continuous changes on consumer preferences on services and market orientation.

The proposed study designs a questionnaire in Likert scale consists of 45 questions and distributes it among 278 managers, randomly. The proposed study use structural equation modeling (SEM) to examine the hypotheses of the survey. Table 1 shows statistics associated with AVE, CR and Cronbach alpha for two items, namely, market orientation and market chaos.

\section{Table 1}

The results of AVE, CR and Cronbach alpha

\begin{tabular}{lccc}
\hline Variable & AVE & CR & Cronbach alpha \\
\hline Market orientation & 0.59 & 0.62 & 0.76 \\
Market chaos & 0.63 & 0.75 & 0.74 \\
\hline
\end{tabular}

The result of Table 1 confirms the validity of the questionnaire and we can use the results of SEM on testing various hypotheses of the survey.

\section{The results}

In this section, we present details of our findings on testing two hypotheses of this paper using SEM model given in Fig. 1. 


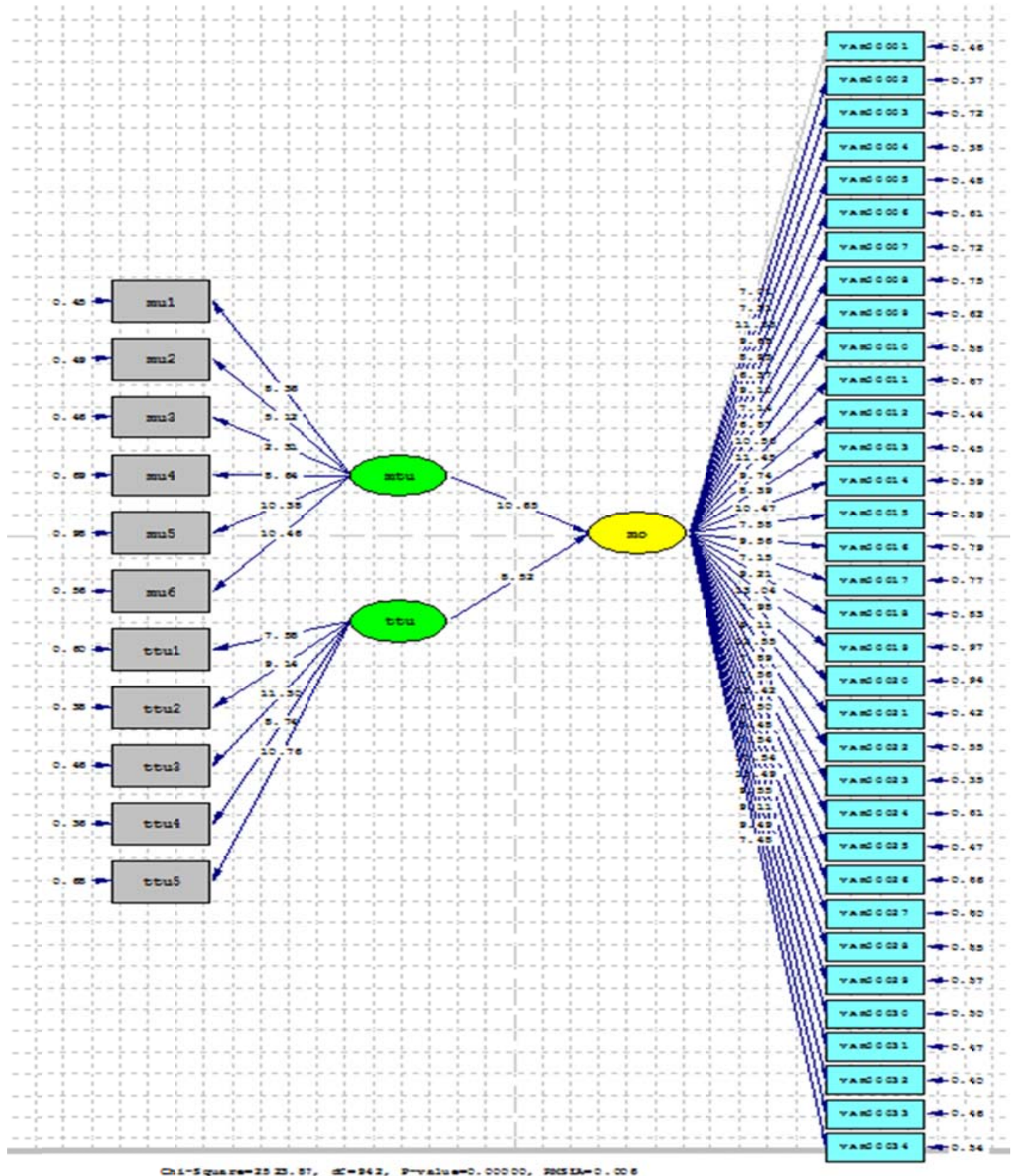

Fig. 1. The results of t-student values for SEM implementation

The results of Fig. 1 indicate that all relationships are statistically meaningful when the level of significance is five percent. In our survey, Chi-square is equal to 2523.57 , $\mathrm{df}=242$ with P-value $=0.000$ and $\mathrm{RMSEA}=0.006$. Table 2 shows details of our findings on testing two hypotheses of the survey.

Table 2

The results of SEM

\begin{tabular}{|c|c|c|c|c|}
\hline Row & Path & $\beta$ & $\mathrm{t}$ & Hypothesis \\
\hline 1 & Mtu-mo & 0.85 & 10.69 & Confirming the main hypothesis \\
\hline 2 & Mtu-mu4 & 0.55 & 8.64 & \multirow{2}{*}{ Confirming the first hypothesis } \\
\hline & Mtu-mu5 & 0.55 & 10.38 & \\
\hline 3 & Mtu-mu6 & 0.49 & 10.46 & Confirming the second hypothesis \\
\hline
\end{tabular}


Based on the results of Table 2, we observe that the main hypothesis of the survey through a path "Mtu-mo" is confirmed, which means any chaos in market influences on market orientation, positively $(\beta=0.85 \mathrm{t}$-value $=10.69)$. In addition, the first and the second sub-hypotheses of the survey have also been confirmed through "Mtu-mu4" and "Mtu-mu5", respectively. Therefore, we can confirm that there was a positive and meaningful relationship between continuous changes on consumer preferences on products and market orientation $(\beta=0.55 \mathrm{t}$-value $=8.64)$. In addition, There is a positive and meaningful relationship between continuous changes on consumer preferences on services and market orientation $(\beta=0.55 \mathrm{t}$-value $=10.38)$.

\section{Conclusion}

In this paper, we have investigated the effects of market orientation on market chaos in fast food industry in Iran. The proposed study has been accomplished among some randomly selected managers who lived in city of Tehran, Iran. The study has applied structural equation modeling to examine two hypotheses of the survey. The results have confirmed that there was a positive and meaningful relationship between continuous changes on consumer preferences on products and market orientation $(\beta=0.55 \mathrm{t}$-value $=8.64)$. In addition, There was a positive and meaningful relationship between continuous changes on consumer preferences on services and market orientation $(\beta=0.55$ t-value $=10.38)$.

\section{Acknowledgement}

The authors would like to thank the anonymous referees for constructive comments on earlier version of this paper.

\section{References}

Agus, A., \& Abdullah, M. (2000). The mediating effect of customer satisfaction on TQM practices and financial performance. Singapore Management Review, 22(2), 55-73.

Baker, W. E., \& Sinkula, J. M. (2007). Does market orientation facilitate balanced innovation programs? An organizational learning perspective. Journal of Product Innovation Management, 24(4), 316-334.

Carmen, C., \& Jose, G. M. (2008). The role of technological and organizational innovation in the relation between market orientation and performance in cultural organizations. European Journal of Innovation Management, 11(3), 413-434.

Durrieu, F., \& Hofmeister, A. T. (2008). Market orientation of French and Hungarian small and medium-sized wineries. International Journal of Wine Business Research, 20(2), 124-137.

Farrell, M. A., Oczkowski, E., \& Kharabsheh, R. (2008). Market orientation, learning orientation and organisational performance in international joint ventures. Asia Pacific Journal of Marketing and Logistics, 20(3), 289-308.

Elg, U. (2007). Market orientation processes in retailing: a cross-national study. European Journal of Marketing, 41(5/6), 568-589.

Han, J. K., Kim, N., \& Srivastava, R. K. (1998). Market orientation and organizational performance: is innovation a missing link?. The Journal of marketing, 62(4), 30-45.

Hurley, R. F., \& Hult, G. T. M. (1998). Innovation, market orientation, and organizational learning: an integration and empirical examination. The Journal of Marketing, 62(3), 42-54.

Ruekert, R. W. (1992). Developing a market orientation: an organizational strategy perspective. International Journal of Research in Marketing, 9(3), 225-245.

Slater, S. F., \& Narver, J. C. (1995). Market orientation and the learning organization. The Journal of Marketing, 59(3), 63-74. 